\title{
Information from financial markets and VAR measures of monetary policy *
}

\author{
Fabio C. Bagliano ${ }^{\dagger}$ and Carlo A. Favero \\ September 1998
}

\begin{abstract}
Exogenous measures of monetary policy shocks, directly derived from financial market information, are used in close (US) and open (US-Germany) economy VAR models to evaluate the robustness of the dynamic effect of monetary policy obtained from traditional identified VAR. The empirical analysis confirms the main features of the monetary policy transmission mechanism in US and Germany, explicitly addressing the issue of simultaneity between the German policy interest rate and the US dollar-DMark exchange rate.
\end{abstract}

JEL classification: E44, E52, F41

Keywords: Monetary Policy, VAR models, exchange rates, implicit forward rate curve.

\section{Introduction}

Over the last 15 years the empirical evaluation of the effects of monetary policy actions has widely used Vector Autoregressive ( VAR) models. Estimation of $V A R$ models for close and open economies has produced a number of reasonably interpretable and therefore generally accepted results and some empirical regularities that still need a final explanation. These puzzles also motivated some of the criticisms addressed to VAR methodology.

\footnotetext{
* Paper prepared for the 1998 annual meeting of the European Economic Association, Berlin, 2-5 September 1998. Financial support from Consiglio Nazionale delle Ricerche is gratefully acknowledged.

† Università di Torino, Dipartimento di Scienze Economiche e Finanziarie "G. Prato", Corso Unione Sovietica 218bis, 10134, Torino, Italy. e-mail: bagliano@econ.unito.it

† Università "L. Bocconi", Via Sarfatti 25, 20136, Milano, Italy and CEPR, London, UK; e-mail: carlo.favero@uni-bocconi.it
} 
The crucial point in the $V A R$ approach to monetary policy analysis is the identification of monetary policy shocks as distinct from monetary policy actions. Policy makers' actions to some extent respond to current developments in the economy; this response is captured by a policy reaction function. The remaining movements in policy instruments, the deviations of authorities from their rule, are interpreted as monetary policy shocks and their effects can be meaningfully investigated by means of the impulse response function techniques. ${ }^{1}$

The use of different identification schemes characterizes the proposed solutions to the empirical puzzles in the $V A R$ literature. The present paper describes a different approach, deriving measures of monetary policy shocks from the information content of financial markets data and using them to evaluate VAR-based measure of monetary policy and strengthen their identification.

In section 2 the fundamental identification problem is stated and the potential role of non- VAR measures of policy shock is discussed. In section 3 some alternative measures of this kind are presented for the US and Germany. Results for the close (US) economy and open (US-Germany) economies are presented in section 4. Section 5 briefly concludes.

\section{The identification issue and the role of non- VAR mea- sures of monetary policy shocks}

The identification problem in the $V A R$ literature may be illustrated in a general framework, ${ }^{2}$ starting from the following structural model of interest:

$$
\mathbf{A}\left(\begin{array}{c}
\mathbf{Y}_{t} \\
\mathbf{M}_{t}
\end{array}\right)=\mathbf{C}(L)\left(\begin{array}{c}
\mathbf{Y}_{t-1} \\
\mathbf{M}_{t-1}
\end{array}\right)+\mathbf{B}\left(\begin{array}{c}
\boldsymbol{\nu}_{t}^{Y} \\
\boldsymbol{\nu}_{t}^{M}
\end{array}\right)
$$

where $\mathbf{Y}$ and $\mathbf{M}$ are vectors of macroeconomic (non-policy) variables (e.g. output and prices) and variables controlled by the monetary policymaker (e.g. interest rates and monetary aggregates containing information on monetary policy actions) respectively. Matrix $\mathbf{A} \equiv\left(\begin{array}{ll}\mathbf{a}^{Y Y} & \mathbf{a}^{Y M} \\ \mathbf{a}^{M Y} & \mathbf{a}^{M M}\end{array}\right)$ describes the contemporaneous relations among the variables and $\mathbf{C}(L)$ is a matrix finite-order lag polynomial.. $\boldsymbol{\nu} \equiv\left(\boldsymbol{\nu}^{Y^{\prime}} \boldsymbol{\nu}^{M^{\prime}}\right)^{\prime}$ is a vector of (unit-variance, orthogonal) structural disturbances to the non-policy and policy variables; non-zero off-diagonal elements of $\mathbf{B}$ allow

\footnotetext{
${ }^{1}$ Christiano, Eichenbaum and Evans (1998) provide a thorough review of the empirical VAR literature.

${ }^{2}$ See Amisano and Giannini (1996), Bernanke and Mihov (1995) and Christiano, Eichenbaum and Evans (1998).
} 
some shocks to affect directly more than one endogenous variable in the system. The estimated VAR is the reduced form of the underlying structural model (2.1):

$$
\left(\begin{array}{c}
\mathbf{Y}_{t} \\
\mathbf{M}_{t}
\end{array}\right)=\mathbf{A}^{-1} \mathbf{C}(L)\left(\begin{array}{c}
\mathbf{Y}_{t-1} \\
\mathbf{M}_{t-1}
\end{array}\right)+\left(\begin{array}{c}
\mathbf{u}_{t}^{Y} \\
\mathbf{u}_{t}^{M}
\end{array}\right)
$$

where $\mathbf{u}$ denotes the $V A R$ residual vector. The relation between the $V A R$ residuals in $\mathbf{u}$ and the structural disturbances in $\boldsymbol{\nu}$ is therefore:

$$
\mathbf{A}\left(\begin{array}{c}
\mathbf{u}_{t}^{Y} \\
\mathbf{u}_{t}^{M}
\end{array}\right)=\mathbf{B}\left(\begin{array}{c}
\nu_{t}^{Y} \\
\nu_{t}^{M}
\end{array}\right)
$$

The identification of the relevant structural parameters, given the estimation of the reduced form, requires the imposition of some restrictions on the elements of $\mathbf{A}$ and $\mathbf{B}$. In fact, given a $V A R$ estimated on a vector of $n$ variables, the maximum number of identifiable structural parameters in $\mathbf{A}$ and $\mathbf{B}$ is equal to $\frac{n(n+1)}{2}$, the number of parameters in the variance-covariance matrix of reduced form residuals.

The main identification strategy followed in the literature is based on restrictions upon the elements of $\mathbf{A}$. Under the commonly adopted recursiveness assumption (in the terminology of Christiano, Eichenbaum and Evans (1998)), identification is achieved by assuming that monetary policy shocks take at least one period to affect macroeconomic variables (i.e. $\mathbf{a}^{Y M}=\mathbf{0}$ ) and by imposing restrictions on the simultaneous relations among monetary variables derived by careful analysis of Central Banks' operating procedures.

Using this set of assumptions, the more recent empirical literature has produced a number of robust results in close-economy applications. In particular, two puzzles that characterized the earlier literature have been solved: the "liquidity puzzle" (when monetary policy shocks are identified as innovations in relatively broad monetary aggregates, positive shocks are associated with nominal interest rate increases) and the "price puzzle" (the positive response of the price level to a contractionary monetary policy shock identified with innovations in interest rates). On the one hand, better specifications of the policy variables in $\mathbf{M}$, including bank reserve aggregates and policy rates whose innovations are identified as monetary policy shocks, provided the negative association between innovations in interest rates and narrow monetary aggregates (liquidity effect) suggested by basic theory. On the other hand, the inclusion of a commodity price index as a leading indicator for domestic inflation in the vector of macroeconomic variables $\mathbf{Y}$, and therefore in the policy reaction function, eliminates the positive response of prices to a contractionary monetary policy shock. ${ }^{3}$

\footnotetext{
${ }^{3}$ See Christiano, Eichenbaum and Evans (1996), Sims (1992) and Bernanke and Blinder (1992).
} 
When the VAR methodology is applied to an open-economy framework, additional complications arise. In fact, when an exchange rate is included in the system, the simultaneous relation between the monetary policy instrument and the exchange rate innovations makes it difficult to correctly identify monetary policy shocks only by means of recursiveness assumptions. Early symptoms of these difficulties are some of the empirical regularities documented, among others, by Eichenbaum and Evans (1995) and Grilli and Roubini (1996b): (i) a contractionary monetary policy shock in the US generates a persistent appreciation of the dollar along with a persistent decrease in the spread between foreign and US interest rates, implying a long-lasting deviation from the uncovered interest parity in favour of US investments (the "forward discount bias" puzzle); (ii) contractionary monetary policy shocks in the G7 countries other than the US are associated with an impact depreciation of their currency relative to the US dollar (the "exchange rate puzzle"). These results are generated by VAR systems where the (US and foreign) policy rates are not allowed to respond contemporaneously to innovations in the exchange rate, e.g. arising from risk premium changes or speculative pressures. The simultaneity issue is not addressed and the resulting identification of monetary policy shocks is questionable.

Some efforts aimed at solving the identification problem in open-economy $V A R$ models have been made, among others, by Grilli and Roubini (1996a), Kim and Roubini (1996), Cushman and Zha (1997) and Smets (1997), for different countries and different sample periods. Despite important differences in specification, the common feature of these papers is that they do not adopt simple recursiveness assumptions, but explicitly address the simultaneity between the interest rate and the exchange rate.

Even though the latter papers present refinements of earlier VAR models, all are in principle subjected to the Rudebusch's (1996) critique of the whole $V A R$ approach to the identification of monetary policy shocks. All VAR models derive policy shocks as innovations with respect to a time-invariant, linear reaction function of the monetary authority, which is assumed to react only to the limited set of variables included in the model. The resulting estimate of monetary policy disturbances may bear little or no relation with the true underlying policy shocks. As an alternative identification strategy, Rudebusch (1996) favours the direct use of expectations of future monetary policy actions embodied in some relevant financial prices.

In the following sections we assess the relevance of some measures of monetary policy shocks derived from financial market prices for the problem of measurement of monetary policy shocks in the close- and open-economy case. We do so by directly including some market-based measures of policy shocks as exogenous variables in two benchmark (close- and open-economy) $V A R$ systems, in which we 
consider the vector of variables $\left(Y_{t}^{U S} P_{c} m_{t} P_{t}^{U S} F F_{t}\right)$ for the close (US) economy, and the vector of variables $\left(\begin{array}{llllllll}Y_{t}^{U S} & P c m_{t} & P_{t}^{U S} & F F_{t} & Y_{t}^{G E R} & P_{t}^{G E R} & R_{t}^{G E R} & e_{t}\end{array}\right)$ for the open (US-Germany) economy in the general structural model (2.1). The variables are defined as follows: $Y^{U S}$ and $Y^{G E R}$ are the logs of US and German industrial production indices, $P \mathrm{~cm}$ is the $\log$ of the commodity price index in US dollars, $P^{U S}$ and $P^{G E R}$ are the logs of US and German consumer price indices, $F F$ is the US effective Federal funds rate, $R^{G E R}$ is the German call money rate, and $e$ is the log of the US dollar/DeutscheMark exchange rate (unit of DMark for one US dollar). In all estimated VAR models, we assume a lower-triangular A and a diagonal B matrix. Estimation is conducted on monthly data over the 1984(1)-1997(11) period with six lags of all variables.

\section{Non- $V A R$ measures of monetary policy shocks}

Several measures of monetary policy shocks derived in various ways from financial markets data have been used in the recent literature.

Rudebusch (1996) constructs a measure of US monetary policy shocks by computing the difference between the Federal funds rate at month $t$ and the 30-day Federal funds rate future at month $t-1$. These unanticipated movements in the policy rate are then regressed on the $V A R$ innovations of the nonpolicy variables, since surprises relative to the information available at the end of month $t-1$ may reflect endogenous policy responses to news on the economy that become available during month $t$. The resulting residual is considered as a reliable measure of the unanticipated part of monetary policy actions for the period starting at the end of 1988, when future contracts on the Fed funds rate were introduced. The sample can be extended by applying the same technique to the future on 1-month Euro-dollar rates (as suggested to us by S. Gerlach), which is available from the beginning of the eighties and produces very similar shocks to the one derived from the Federal funds future for the overlapping sample. For an even longer sample, starting in the mid-'70s, Skinner and Zettelmeyer (1996) use the change in the three-month US Treasury bill rate on the days of policy announcements, selected from central bank reports and newspaper information..

An alternative approach to the construction of a measure of monetary policy shocks directly using financial markets data has been implemented by Bagliano and Favero (1998), applying the methodology set out in Svensson (1994) and Soderlind and Svensson (1997). The methodology is based on the derivation of instantaneous forward rates from estimation of a continuous zero-coupon (spot) yield curve. Since the observable equivalent of the instantaneous forward rate is the overnight (policy) rate, the curve of forward rates can be interpreted as an 
indicator of expected monetary policy, based on the pure expectation theory of the term structure of interest rates. Focusing on the dates of the FOMC meetings (regularly held eight times per year from 1994), monetary policy shocks may be obtained as the difference between the target rate decided upon in the meeting and the forward rate for the day after the meeting implicit in the spot yield curve estimated the day before the meeting. ${ }^{4}$ The same procedure has been applied to the dates of policy announcements used by Skinner and Zettelmeyer (1996) for the period 1988-1993 and the resulting series, labelled IF $S^{U S}$, has been used in Bagliano and Favero (1998).

Using the 1-month Euro-dollar future measure of shocks, labelled EUR $\$$, we can present estimates over an extended sample starting in 1984. The stability analysis of the benchmark VAR conducted in Bagliano and Favero (1998) showed that the 1984-1997 period does not suffer from structural breaks due to important monetary policy regime shifts and therefore can be reasonably considered appropriate for monetary policy analysis.

Figure 1.1 shows the EUR $\$$ series and the monetary policy shock series $\left(\nu^{F F}\right)$ obtained from as the orthogonalized residual from the equation for $F F$ in the close economy $V A R$ (three-month centered moving averages are computed to make the comparison easier). Figure 1.2 shows the IFS $S^{U S}$ and $\nu^{F F}$ series. Table 1.A reports correlations between the above alternative measures of monetary policy shocks (and standard errors on the diagonal). The correlations between the non$V A R$ measures of policy shocks and the benchmark VAR residuals are relatively low, ranging from 0.3 to 0.5 . However, when the $E U R \$$ and IF $S^{U S}$ series are included in the system as exogenous variables, the estimated impact coefficients (highly statistically significant in the equation for the policy rate) support the fact that these non- VAR measures capture important innovations in the Federal funds rate.

We have also applied the implied forward rate methodology to Germany, where monetary policy actions are taken at the Bundesbank Council meetings, regularly held every two weeks (an information available to the public). > From 1983 onwards, we estimated a smooth spot yield curve on each day before a Council meeting and determined the curve of implied istantaneous forward rates. Therefore, we are able to compute the overnight interest rate expected for the day following the Council. The difference between the realized overnight interest rate the day after the Council meeting and the expected overnight interest rate for that day, conditional upon information available before the meeting, is our mea-

\footnotetext{
${ }^{4}$ The estimated curve is fitted to the following rates: the federal fund target, 1-, 3-, 6- and 12-month euro, 3-, 5-, 7- and 10-year fixed interest rate swap. Further details are provided in Bagliano and Favero (1998).
} 
sure of monetary policy shocks for Germany, labelled IF $S^{G E R} .5$ Figure 1.3 shows three-month moving averages of $I F S^{G E R}$ and of the orthogonalized residual for the German call money rate equation in the open economy $V A R, \nu^{R G E R}$. Table $2 . B$ reports a low correlation $(0.16)$ between the two variables; however, the impact coefficient on $I F S^{G E R}$ when included in the system is statistically significant. As for the US measures, also for Germany this measure is able to capture some variability in the policy rate.

In the following section we investigate the dynamic response of macroeconomic variables to movements in our monetary policy shock measure, in both the close and the open economy version of the $V A R$ system.

\section{Empirical results on the effect of monetary policy}

\subsection{Close economy (US)}

To evaluate the role of non- VAR based measures of monetary policy shock, we first estimate the close-economy four-variable version of the $V A R$ model in (2.2) for the US and compute impulse response functions of all variables to a shock in the Federal funds rate. The ordering chosen allows for a contemporaneous response of the policy rate to innovations in output, consumer prices and the commodity price level. The orthogonalized residual of the Federal funds rate equation, $\nu^{F F}$, is identified as a monetary policy shock. No structural interpretation is given to the (orthogonalized) residuals from the other equations in the system. The impulse responses are shown, along with one-standard deviation bands, in Figure 2 as the dotted lines.

A contractionary monetary policy shock produces the expected negative effect on output and a persistent effect on the Federal funds rate. The inclusion of the commodity price index is successful in solving the price puzzle: the consumer price level does not show a perverse response to restrictive policy.

\footnotetext{
${ }^{5}$ Standard practice in the application of this methodology includes the overnight rate in the information set and sometime constrains estimation so that the fitted overnight rate matches the observed one. However, a monetary policy shock implies by definition a jump in, at least, the short end of the term structure. Forcing the smooth instantaneous forward rate curve to fit exactly the observed overnight rate would not allow to seize an eventual expected monetary policy action. We therefore exclude the overnight rate from the information used for estimation. Exploiting then the continuity of the functional form we reconstruct the very short end of the term structure allowing for a gap between the estimated overnight and the observed overnight. Such gap represents the jump in the very short-end of the term structure associated with expectations of intervention by the Council. The rates used in estimation are then the one-week rate, the 1-, 3-, 6-, and 12-month Euro, and the 3-, 5-, 7- and 10-year fixed rate swap. Further details are provided in Bagliano, Favero and Franco (1998).
} 
Now our measure of monetary policy shocks derived from the one-month Eurodollar forward rate $(E U R \$)$ is included in the $V A R$ as exogenous variable. The estimated system becomes:

$$
\mathbf{A}\left(\begin{array}{c}
Y_{t}^{U S} \\
P c m_{t} \\
P_{t}^{U S} \\
F F_{t}
\end{array}\right)=\mathbf{C}(L)\left(\begin{array}{c}
Y_{t-1}^{U S} \\
P c m_{t-1} \\
P_{t-1}^{U S} \\
F F_{t-1}
\end{array}\right)+\left(\begin{array}{c}
g_{1} \\
g_{2} \\
g_{3} \\
g_{4}
\end{array}\right) E U R \oiint_{t}+\mathbf{B}\left(\begin{array}{c}
\nu_{t}^{1} \\
\nu_{t}^{2} \\
\nu_{t}^{3} \\
\nu_{t}^{F F}
\end{array}\right)
$$

Estimation is carried out keeping the same assumptions on $\mathbf{A}$ and $\mathbf{B}$ made above. The estimated values of the coefficients $g_{i}$ are reported in Table 1.A and the dynamic responses of all endogenous variables to a monetary policy shock measured by EUR $\$$ are shown in Figure 2 as the solid lines. The main features of the effects of monetary policy shocks already detected in the benchmark system are confirmed here, as the two impulse response functions describe a very similar transmission mechanism, supporting the evidence already provided by Brunner (1996) and Bagliano and Favero (1998) with different exogenous measures. Despite a correlation of 0.5 between $E U R \$$ and the measure of policy shock obtained from the benchmark $V A R$, the dynamic effects of monetary policy show very close features: both measures capture unexpected variations in the policy rate related to monetary policy and the existence of other non-policy disturbances does not change the basic features of the response to a policy shock. Finally, as shown in the first row of Table 2, the estimated coefficients of the policy reaction function show that the policy rate positively reacts to innovations in output and the price level.

\subsection{Open economy (US-Germany)}

Let us now consider the open-economy version of the $V A R$ system in (2.2). The dynamic responses of all endogenous variables to a German monetary policy shock identified as the orthogonalized residual of the German call money rate equation $\left(\nu^{R G E R}\right)$ are shown in Figure 2 as the dotted lines, along with one-standard deviation bands. The responses of German output, prices and the policy rate are consistent with the results obtained for the US. In particular, we note that the response of consumer prices to a contractionary monetary policy shock is as expected. The response of the exchange rate shows an impact depreciation of the DMark which is not strongly significant, followed by some months of appreciation. The estimated standard errors, however, are fairly large and do not allow sharp inference on the dynamic behaviour of the exchange rate.

As in the close-economy case, we augment the previously estimated system by including the exogenous measure of German monetary policy shocks $I F S^{G E R}$ 
described in the previous section. The open-economy $V A R$ is now the following:

$$
\mathbf{A}\left(\begin{array}{c}
Y_{t}^{U S} \\
P c m_{t} \\
P_{t}^{U S} \\
F F_{t} \\
Y_{t}^{G E R} \\
P_{t}^{G E R} \\
e_{t} \\
R_{t}^{G E R}
\end{array}\right)=\mathbf{C}(L)\left(\begin{array}{c}
Y_{t-1}^{U S} \\
P c m_{t-1} \\
P_{t-1}^{U S} \\
F F_{t-1} \\
Y_{t-1}^{G E R} \\
P_{t-1}^{G E R} \\
e_{t-1} \\
R_{t-1}^{G E R}
\end{array}\right)+\left(\begin{array}{c}
g_{1} \\
g_{2} \\
g_{3} \\
g_{4} \\
g_{5} \\
g_{6} \\
g_{7} \\
g_{8}
\end{array}\right) I F S_{t}^{G E R}+\mathbf{B}\left(\begin{array}{c}
\nu_{t}^{1} \\
\nu_{t}^{2} \\
\nu_{t}^{3} \\
\nu_{t}^{F F} \\
\nu_{t}^{5} \\
\nu_{t}^{6} \\
\nu_{t}^{e} \\
\nu_{t}^{R G E R}
\end{array}\right)
$$

Using our exogenous measure of monetary policy shocks in combination with a Choleski ordering with the German policy rate coming last, we are able to directly address the issue of simultaneity between German monetary policy and the exchange rate. The contemporaneous effect of a monetary policy shock on the exchange rate is given by the coefficient on $I F S^{G E R}$ in the exchange rate equation $\left(g_{7}\right)$, while the response of the German interest rate to innovations in the exchange rate is endogenized by the ordering chosen.

The impulse response functions shown in Figure 2 with solid lines confirm qualitatively the results obtained for the close US economy: measuring monetary policy shocks using financial market data does not alter the main features of the monetary transmission mechanism for Germany. As shown in Table 1.B the impact coefficient of $I F S^{G E R}$ is significant in the equation for the German call money rate (supporting the view that our measure captures some important unanticipated movements in the policy rate) but not in the exchange rate equation. No impact depreciation of the DMark is detected, and the subsequent response of $e$ shows an appreciation for the first five months after the shock, followed by a depreciation. From the estimated coefficients of the policy reaction functions reported in Table 2 we note that the endogenous response of the US Federal funds rate is unchanged with respect to the close-economy case and the German policy rate responds significantly only to innovations in the German consumer price index, signalling inflationary pressures. No significant response to the exchange rate is detected. This latter result, along with the previous observation of no significant impact of monetary policy shocks on the exchange rate, suggests that the potential simultaneity between the exchange rate and the German policy rate is not an empirically relevant problem. Finally, the last row of Table 2 shows that innovations in the exchange rate are positively related to fluctuations in US output, German prices and the US Federal funds rate. 


\section{Conclusions}

This paper presented some evidence on the effects of monetary policy shocks in close (US) and open (US-Germany) economies when exogenous, non-VAR measures of policy disturbances are used. Such measures are directly derived from financial market prices and do not rely on specific identification assumptions imposed in the estimation of the $V A R$ system.

The use of non-VAR measures of policy shocks may be useful in evaluating the robustness of the dynamic effect of monetary policy obtained from traditional identified $V A R$, since it may help to solve the simultaneity problem between policy instruments and other endogenous variables to which monetary policy systematically reacts. Our empirical analysis confirms the main features of the monetary policy transmission mechanism in US and Germany, explicitly addressing the issue of simultaneity between the German policy interest rate and the US dollar-DMark exchange rate.

Future research in this direction can widen the direct use of financial market information to evaluate the effects of monetary policy. For example, prices of interest rate (Euro) options provide implicit measures of the uncertainty surrounding monetary policy. Such measures might then be used to assess the effects of "uncertainty shocks" on interest rates and macroeconomic quantities.

\section{References}

[1] Amisano G. and C.Giannini (1996) Topics in Structural VAR Econometrics, Springer-Verlag

[2] Bagliano F.-C. and C.A. Favero (1998) "Measuring Monetary Policy with VAR models: an evaluation", European Economic Review, 42, 6, 1069-1112

[3] Bagliano F.-C., C.A. Favero and F. Franco (1998) "Measuring Monetary Policy in Open Economies", mimeo

[4] Bernanke B.S. and A. Blinder (1992) "The Federal Funds Rate and the channels of monetary transmission", American Economic Review, 82, 901-921

[5] Bernanke B.S. and I. Mihov (1995) "Measuring monetary policy", NBER working paper n. 5145

[6] Brunner A. (1996) "Using measures of expectations to identify the effects of a monetary policy shock", Board of Governors of the Federal Reserve System, International Finance Discussion Paper n.537 
[7] Christiano L.J., M. Eichenbaum and C.L. Evans (1996) "The Effects of Monetary Policy Shocks: Evidence from the Flow of Funds", Review of Economics and Statistics, 78, 16-34

[8] Christano L.J., M.Eichenbaum and C.Evans (1998) "Monetary Policy shocks: what have we learned and to what end?" NBER working paper 6400

[9] Cushman D.O. and T. Zha (1997) "Identifying Monetary Policy in a Small Open Economy under Flexible Exchange Rates", Journal of Monetary Economics, 39, 433-448

[10] Eichenbaum M. and C.Evans (1995) "Some Empirical Evidence on the effects of monetary policy on exchange rates", Quarterly Journal of Economics, 110, 975-1009

[11] Grilli V. and N. Roubini (1996a) "Liquidity and Exchange Rates: Puzzling Evidence from the G-7 Countries", mimeo, Yale University

[12] Grilli V. and N. Roubini (1996b) "Liquidity Models in Open Economies: Theory and Empirical Evidence", European Economic Review, 4, 847-859

[13] Kim S. and N.Roubini (1996) "Liquidity and Fxchange Rates in the G-7 Countries: Evidence from identified VARs", mimeo

[14] Rudebusch G.D. (1996) "Do Measures of Monetary Policy in a VAR Make Sense?", Temi di Discussione n.269, Bank of Italy

[15] Sims C.A. (1992) "Interpreting the Macroeconomic Time-Series Facts: the Effects of Monetary Policy", European Economic Review, 36, 975-1011

[16] Skinner T. and J. Zettelmeyer (1996) "Identification and effects of monetary policy shocks: an alternative approach", mimeo, MIT, September

[17] Smets F.(1997) "Measuring Monetary Policy Shocks in France, Germany and Italy: the role of the exchange rate", BIS working paper no. 42

[18] Soderlind P and L.E.O. Svensson (1997) "New techniques to extract market expectations from financial instruments", Journal of Monetary Economics, $40,383-42$

[19] Svensson L.E.O. (1994) "Estimating and interpreting forward interest rates: Sweden 1992-1994", CEPR Discussion Paper n.1051 
Table 1

Correlations between benchmark VAR and non-VAR monetary policy shocks

\section{A. Close Economy}

Correlation coefficients (standard errors on the diagonal)

Sample: 1988(11)-1996(10)

\begin{tabular}{cccc}
\multicolumn{1}{c}{} & $E U R \$$ & IFS & $\nu^{\text {ES }}$ \\
\cline { 2 - 4 } $\operatorname{EUR} \$$ & 0.185 & & \\
$\operatorname{IFS} S^{U S}$ & 0.203 & 0.169 & \\
$\nu^{F F}$ & 0.352 & 0.319 & 0.123
\end{tabular}

Coefficients on $E U R \$$ and $I F S^{U S}$ in the close-economy $V A R$

$\begin{array}{lllll} & Y^{U S} & P c m & P^{U S} & F F \\ E U R \$ & 0.0061 & 0.0055 & 0.0013 & \mathbf{0 . 4 6 8} \\ & \mathbf{( 0 . 0 0 3 2 )} & (\mathbf{0 . 0 1 2 1 )} & (1.0633) & \mathbf{( 0 . 0 9 7 )} \\ \text { IFS } & \mathbf{0 . 0 0 2 5} & \mathbf{0 . 0 0 8 2} & 0.0009 & \mathbf{0 . 3 5 6} \\ & \mathbf{( 0 . 0 0 3 1 )} & \mathbf{( 0 . 0 1 1 6 )} & \mathbf{( 0 . 0 0 1 3 )} & \mathbf{( 0 . 0 9 9 )}\end{array}$

Sample: 1984(1)-1997(11)

\begin{tabular}{|c|c|c|c|c|}
\hline & & $E U R \$$ & $\nu^{F F}$ & \\
\hline & $E U R \$$ & 0.277 & & \\
\hline & $\nu^{F F}$ & 0.500 & 0.211 & \\
\hline & $Y^{U S}$ & Pcm & $P^{U S}$ & $F F$ \\
\hline$E U R \$$ & $\begin{array}{l}0.0026 \\
(0.0016)\end{array}$ & $\begin{array}{l}0.0007 \\
(0.0006)\end{array}$ & $\begin{array}{l}0.0058 \\
(0.0063)\end{array}$ & $\begin{array}{l}0.552 \\
(0.062)\end{array}$ \\
\hline
\end{tabular}

\section{B. Open Economy}

Sample: 1984(1)-1997(11)

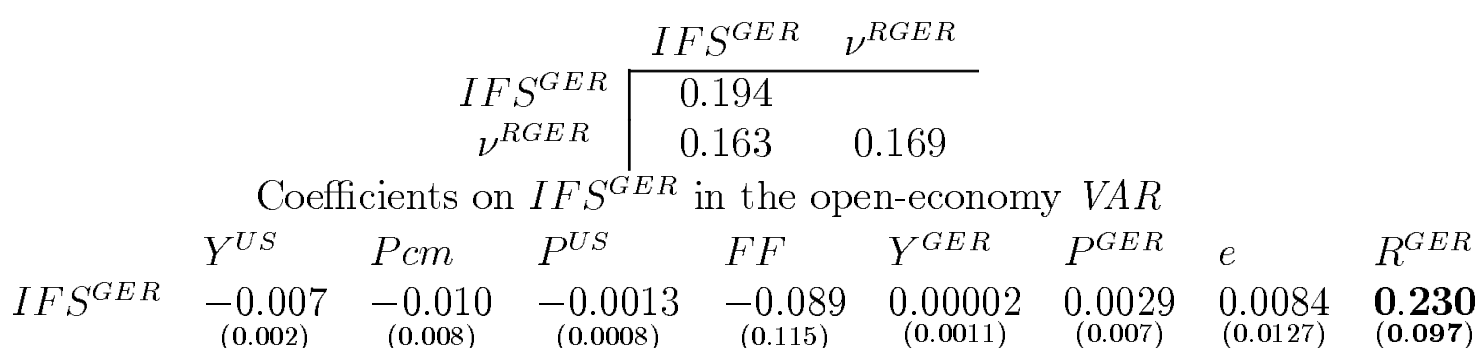


Table 2

The simultaneous determinants of US and German policy rates and of the US dollar/D. Mark exchange rate

Based on the benchmark VAR models in close and open economy (1984-1997)

( ${ }^{+}$denotes the standard error of the corresponding residual)

\begin{tabular}{|c|c|c|c|c|c|c|c|c|}
\hline & $Y^{U S}$ & Pcm & $P^{U S}$ & $F F$ & $Y^{G E R}$ & $P^{G E R}$ & $e$ & $I F S^{G E R}$ \\
\hline FF US close & $\begin{array}{c}0.090 \\
(0.033)\end{array}$ & $\begin{array}{c}0.017 \\
\mathbf{( 0 . 0 0 9 9 )}\end{array}$ & $\begin{array}{c}0.262 \\
(0.094)\end{array}$ & $0.207^{+}$ & - & - & - & - \\
\hline$F F U S$ open & $\begin{array}{c}0.090 \\
(0.035)\end{array}$ & $\begin{array}{l}0.013 \\
(0.010)\end{array}$ & $\begin{array}{c}0.378 \\
(0.095)\end{array}$ & $0.178^{+}$ & 0 & 0 & 0 & $\begin{array}{c}-0.089 \\
(0.115)\end{array}$ \\
\hline$R^{G E R}$ & $\begin{array}{c}-0.015 \\
(0.032)\end{array}$ & $\begin{array}{c}-0.004 \\
(0.009)\end{array}$ & $\begin{array}{c}-0.048 \\
(\mathbf{0 . 0 8 9 )}\end{array}$ & $\begin{array}{l}0.015 \\
(0.070)\end{array}$ & $\underset{(0.010)}{0.025}$ & $\begin{array}{c}-0.098 \\
(0.066)\end{array}$ & $\begin{array}{l}0.004 \\
(0.006)\end{array}$ & $\begin{array}{l}0.230 \\
(0.097)\end{array}$ \\
\hline$e$ & $\underset{(0.375)}{\mathbf{1 . 3 5 5}}$ & $\begin{array}{c}-0.148 \\
(0.111)\end{array}$ & $\begin{array}{c}-0.150 \\
(1.101)\end{array}$ & $\underset{(0.008)}{0.022}$ & $\begin{array}{l}0.045 \\
(0.126)\end{array}$ & $\begin{array}{l}2.440 \\
(0.787)\end{array}$ & $0.019^{+}$ & $\begin{array}{l}0.0084 \\
(0.0127)\end{array}$ \\
\hline
\end{tabular}


Figure 1

VAR and non-VAR measures of monetary policy shocks

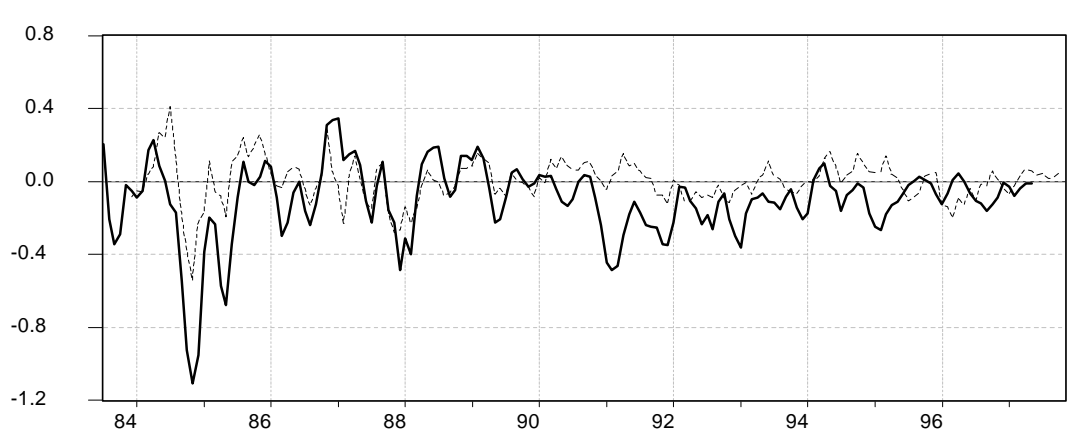

1.1. Three-month centered moving averages of $E U R \$$ shocks (solid line) and close economy $V A R$ monetary policy shocks (dotted line)

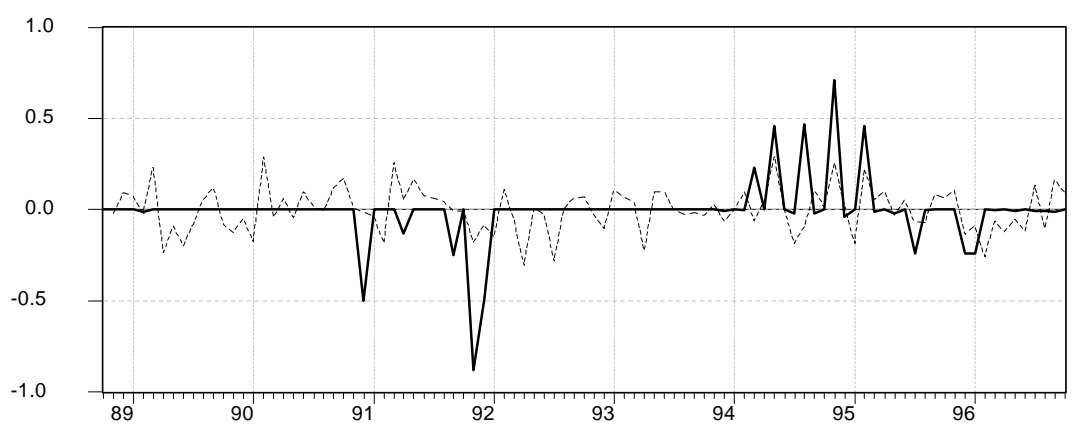

1.2. $I F S^{U S}$ shocks (solid line) and close economy $V A R$ monetary policy shocks (dotted line)

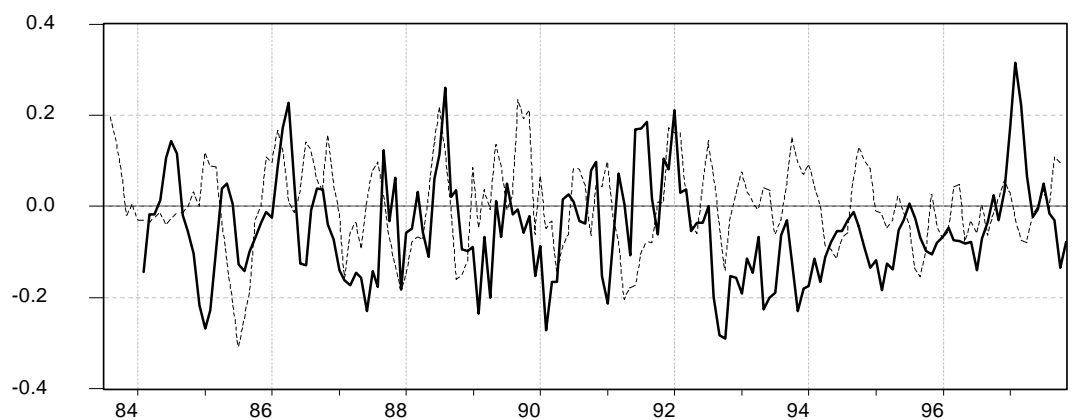

1.3. Three-month centered moving averages of $I F S^{G E R}$ shocks (solid line) and open economy VAR German monetary policy shocks (dotted line) 


\section{Figure 2}

Impulse responses to alternative U.S. monetary policy shocks

\section{in close economy}

Responses to $E U R \$$ shocks (solid line) and to $V A R$-based structural shocks $\nu^{F F}$

(dotted line) with one standard deviation confidence intervals from the benchmark $V A R$
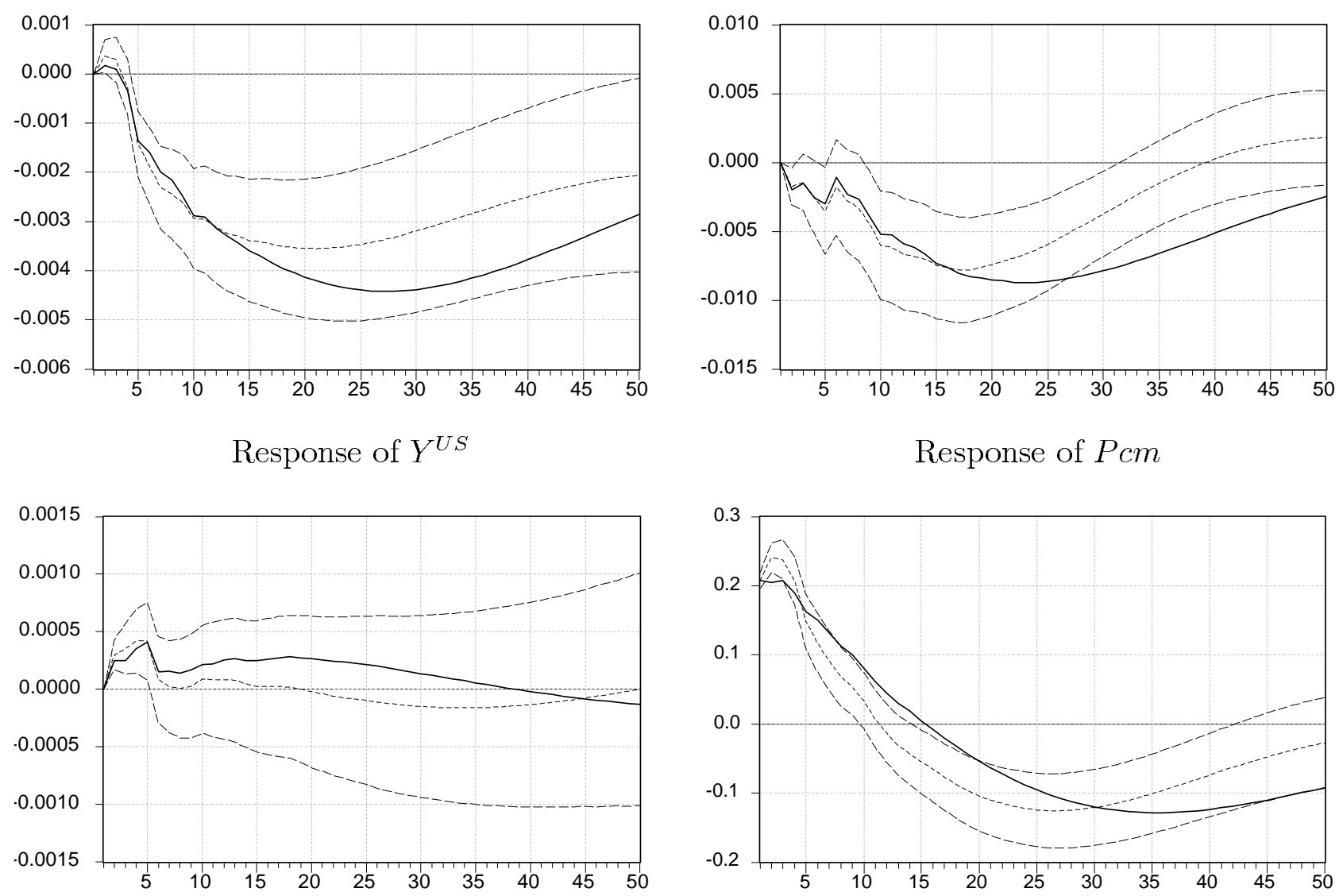

Response of $P^{U S}$

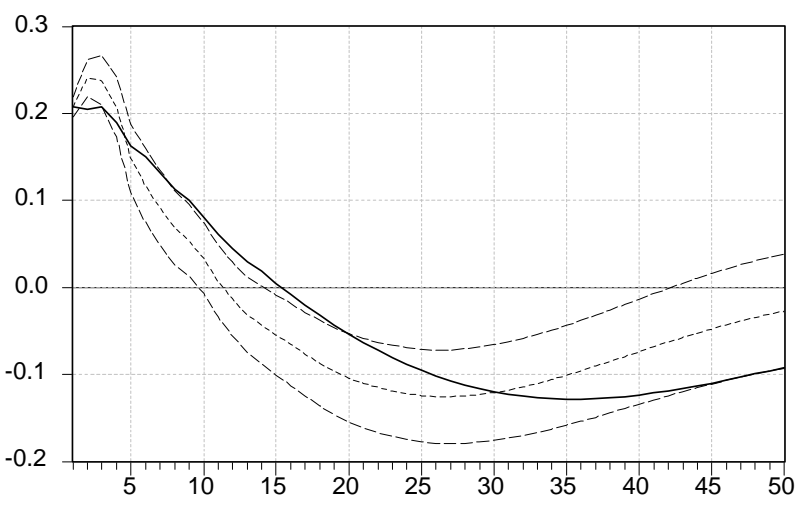

Response of $F F$ 
Figure 3

Impulse responses to alternative German monetary policy shocks in open economy

Responses to IFSGER shocks (solid line) and to VAR-based structural shocks $\nu^{R G E R}$ (dotted line) with one standard deviation confidence intervals from the benchmark $V A R$

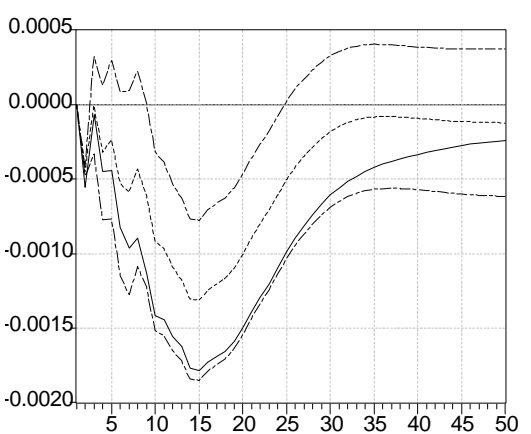

Response of $Y^{U S}$

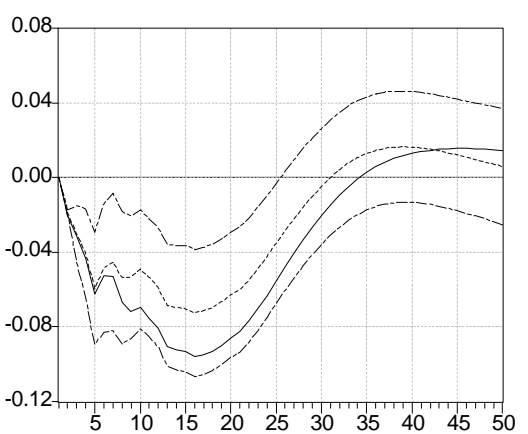

Response of $F F$

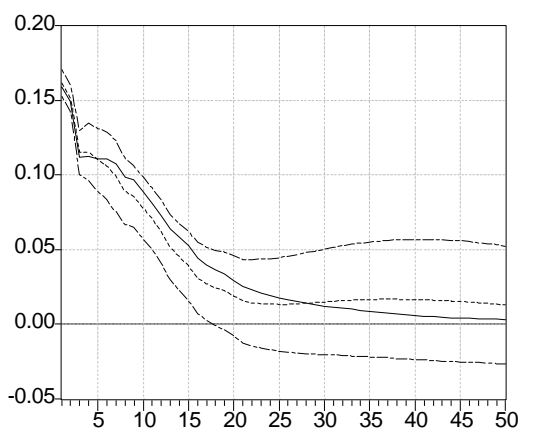

Response of $R^{G E R}$

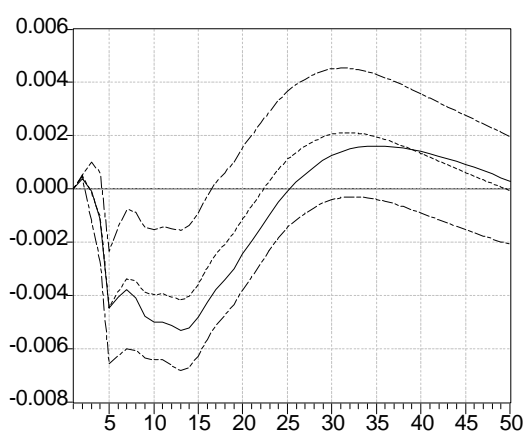

Response of $\mathrm{Pcm}$

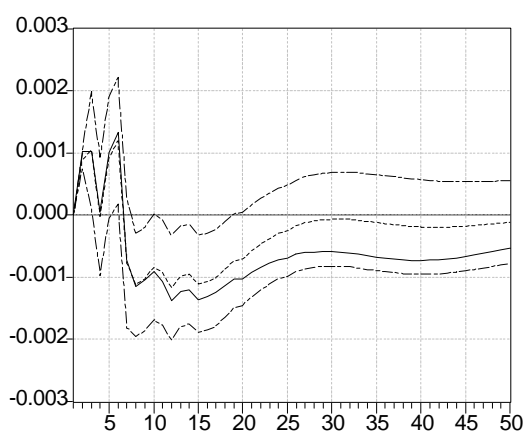

Response of $Y^{G E R}$

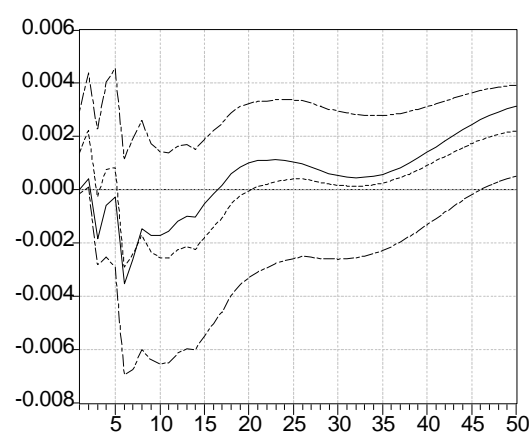

Response of $e$

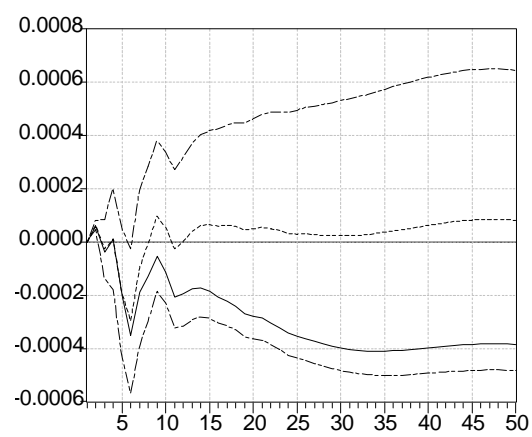

Response of $P^{U S}$

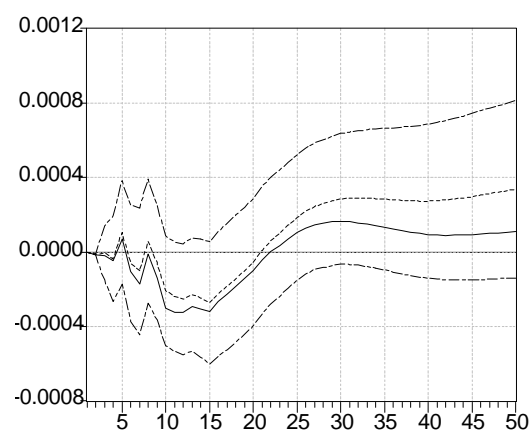

Response of $P^{G E R}$ 